\title{
King's model for allocating service increment for teaching and research (SIFTR)
}

\author{
Gillian B Clack, Gwyn Bevan, Timothy J Peters, Adrian L W F Eddleston
}

Teaching hospitals are more expensive than nonteaching hospitals. This is recognised by the Department of Health, which pays additional resource, the service increment for teaching and research (SIFTR), to compensate them for the extra costs incurred in providing service facilities to support undergraduate teaching and research. Since the NHS reforms in April 1990 this resource has to be targeted at where teaching and research actually happen and set against a medical education contract. Previously it was part of the provider unit's global budget and not allocated separately.

Our medical school has developed a model for the distribution of SIFTR taking into account the recommendations of the steering group on undergraduate medical and dental education. These recommendations were, firstly, that the universities and the NHS should be discouraged from attempting to disaggregate the "knock for knock" arrangements between the hospital and school in respect of medical staff time and, secondly, that the following factors should affect how costs arise: the quantity and intensity of teaching activity; the extent of non-commercially funded research activity; the higher infrastructural costs of hospitals supporting teaching and research; and the extent to which teaching and research require higher numbers of complex cases and more complex treatment of straightforward cases. ${ }^{1}$

\section{Method}

In the King's model $0 \cdot 25 \%$ of SIFTR is taken to cover the costs of monitoring the contract. The remaining money is then divided between teaching and research in the ratio 75:25, which is in line with the University of London's strategy on SIFTR. ${ }^{2}$ The school is, however, convinced that it is impossible to separate out the research and teaching activities of clinical academic staff. The difficulty of joint product costing has been highlighted elsewhere. ${ }^{134}$ The $25 \%$ should be regarded, therefore, as reflecting the impact of "pure research" not linked to teaching, and the arbitrary nature of this percentage is acknowledged.

The model then recommends a transfer of SIFTR to district general hospitals only if a unit attracts five or more full time equivalent students a year. The transfer should then reflect only the direct service costs (calculated to be $15 \%$ of the per capita unit of resource) since it is not necessary to create at these outlying centres the core infrastructure support required in a main university hospital. ${ }^{2}$

The remainder is then distributed within the main university hospital between the specialties. The allocation is used to determine hospital pricing, by using proxy measures of teaching and research activity and correcting for estimated excess costs in each contract area. If it was necessary to divide SIFTR between two or more main university hospitals the same approach would be adopted.

\section{Calculation of clinical student load for firm $X$ with four to five students attached at a time for six modules of eight weeks each year}

On average four to five students are on the firm for 48 weeks a year:

Therefore, the full time equivalent $=4 \cdot 5 \times 48 / 52=4 \cdot 15$

But throughout the year one half day is free for sports and one half day is devoted to lectures, so the students take part in clinical work for eight out of the 10 sessions a week:

Therefore, the revised full time equivalent $=4 \cdot 15 \times 8 / 10=3 \cdot 32$

But during each week there is also a one hour radiology tutorial - that is, one quarter of a session:

Thus, the full time equivalent to radiology from firm $X=1 / 4 \times 1 / 10 \times 4 \cdot 15=0 \cdot 10$

Therefore, the net full time equivalent for firm X $=3 \cdot 32-0 \cdot 10=3 \cdot 22$

In the case of teaching, undergraduate student load expressed in full time equivalents has been used. This load includes not only direct teaching episodes but also occasions when students learn independently in clinical areas-for example, ward clerking. All lectures and practicals not situated in patient areas have been excluded.

The box shows the calculation for a hypothetical firm. The clinical student load has been calculated for all teaching firms and assigned to specialties. The resulting percentage share of the clinical curriculum can then be derived for all contract heads within specialties and used to allocate the teaching component of SIFTR.

For research we sought to identify proxy measures of "non-commercially funded research activity"' and selected the following measures: numbers of research staff financed by departmental research grant money; numbers of full time research postgraduate students; numbers of non-clinical and clinical academic staff; and numbers of NHS consultant and junior medical staff. The last category was given one third of the weighting of the other three categories since these staff were thought to have less research impact than the other three.

Research income was rejected as a measure since it can be used to purchase equipment or consumables, and the number of applications to ethics committees was also rejected on the grounds that these are made in advance of grant applications so would count projects which never took place. The data were collected, assigned to departments, and the resulting percentage share applied to the research component of SIFTR to allocate it to the contract heads.

The final SIFTR allocation was made by adding the
Correspondence to: Miss Clack. 
teaching and research entitlements together, thereby arriving at an initial SIFTR distribution by contract head.

Since SIFTR is meant to offset the justifiable excess costs of the provider unit these were also built into the model. An estimate of excess costs for each contract head was obtained by comparing costs of King's Healthcare in each specialty to national average costs derived from Chartered Institute of Public Finance and Accountancy returns. ${ }^{45}$

The initial allocations of SIFTR were then weighted according to the data on excess costs to provide the final distribution. These sums were then subtracted from the unadjusted unit prices, as determined by aggregation of costs, to arrive at market prices for negotiating contracts for 1992-3. The whole process is shown in figure 1.

The SIFTR allocations are intended to set prices which are comparable with those of non-teaching hospitals and, over time, to finance the service costs of teaching and research. It is difficult to validate the costs of teaching and research because this requires resolving the problem of costing joint products. We have, however, examined how the impact of SIFTR allocations on costs relates to how the prices of King's district specialties compared with regional average prices (fig 2). While there are obvious outlying data points, there is a tendency $(r=0.54)$ for those specialties whose unadjusted prices are higher than the regional average to be allocated more than average of SIFTR. Specialties

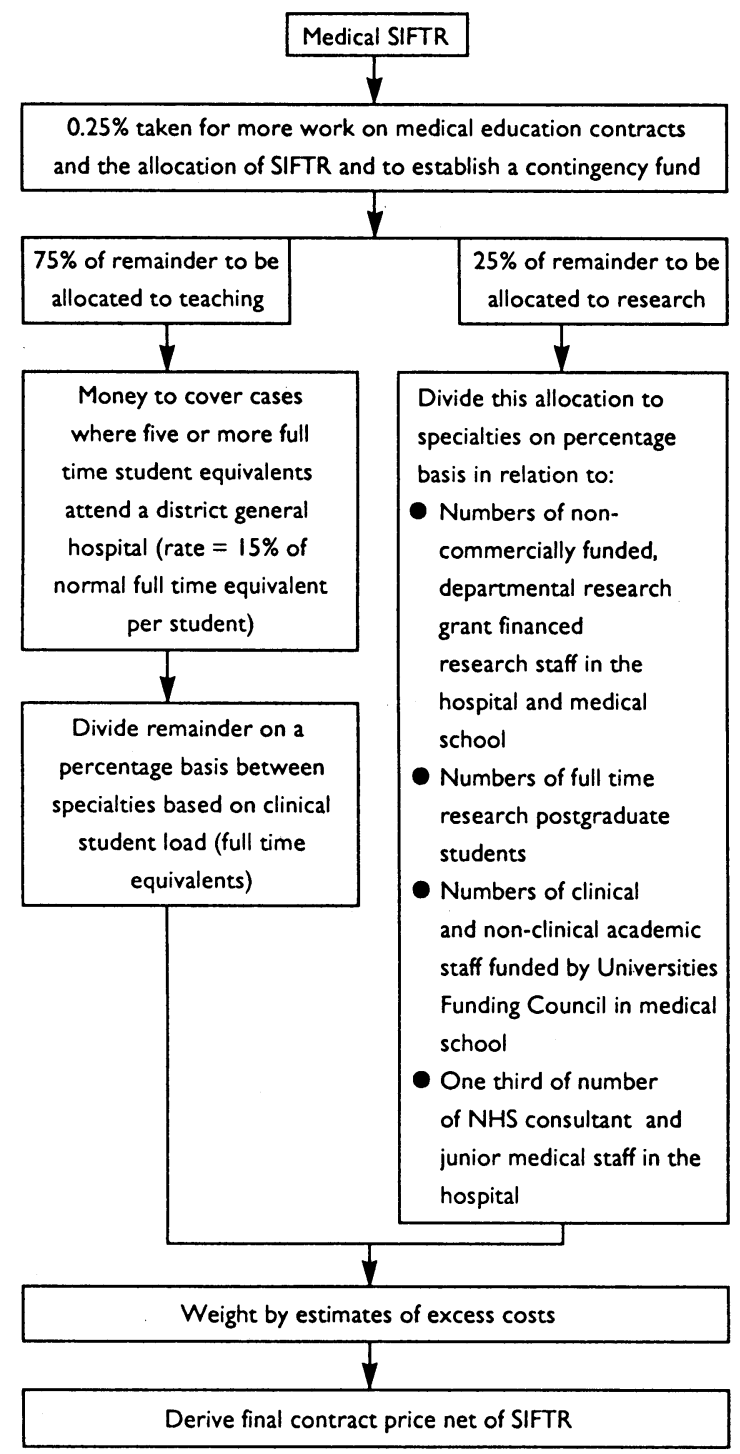

FIG 1-Flow chart of system for allocating SIFTR at King's College Hospital

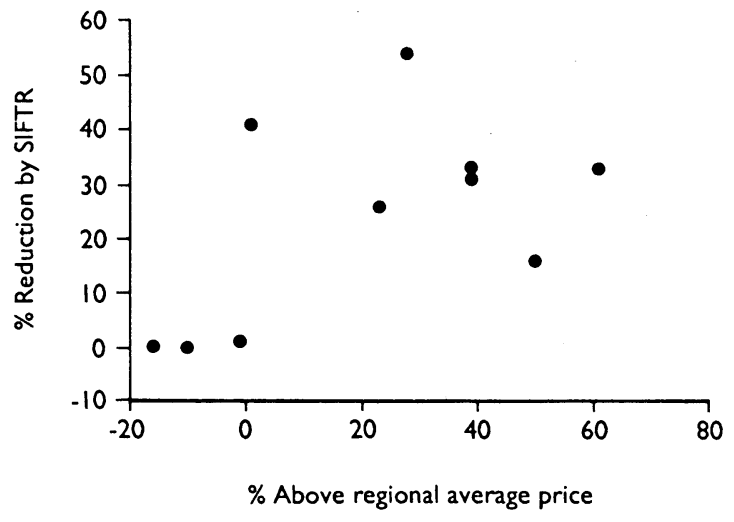

FIG 2-Relation for 10 district specialties, between the percentage reduction in contract price resulting from the final SIFTR allocation and the percentage by which the unadjusted contract price for each specialty was above the regional average price

with prices lower than the regional average received almost no SIFTR.

\section{Discussion}

The advantages of our model are that it enables the provider unit to set fair contract prices (net of SIFTR) that are comparable with those of non-university hospitals; it is derived from readily available data on teaching and research activity and excess costs; and it enables critical analysis of the costs of service support for teaching and research.

During 1992-3 we intend to work on the model to identify and investigate the discrepancies between the excess cost data and SIFTR allocations and to allow SIFTR to be incorporated into budgets. To this end we have devised a method for identifying additional diagnostic investigations, the cost of which will need to be transferred from the clinical care groups to the service departments. Further investigations are likely to include: possible unnecessary diagnostic investigations-a question for medical audit; more analysis of case mix and severity; the influence of social deprivation on medical costs; the relative impact of the same teaching and research load on different departments; whether there are more cost effective teaching methods which could be used without loss of quality; whether more teaching could be done off site-for example, in the community; whether there are unknown factors influencing costs, including unrevealed service research and development. This next stage of the research will eventually lead to more direct estimates of the service support needed for teaching and research

We thank other members of the King's SIFTR working group-Professor I Benjamin, Professor S Campbell, Professor R Higgs, Professor A M McGregor, and Mr I C Turner - who provided data and contributed to the discussions on the criteria to be used in the model at all stages. We also thank the following representatives of King's Healthcare: Mr D Tkaczyk (director of finance), Ms L O'Brien (deputy director of finance), and Ms C Taylor (divisional general manager, community and family services), who have now joined the group, and will be helping with the development of the work in the future. We thank Miss C Hogg, medical school librarian, for help in preparing this paper.

1 Steering Group on Undergraduate Medical and Dental Education. Second report of the steering group. London: Department of Health, 1990.

2 University of London. University strategy on Service Increment for Teaching and Research (SIFTR). London: The University, 1991.

3 Perrin J. The costs and joint products of English teaching hospitals. Financial Accountability and Management 1987;3:209-30.

4 Camberwell Health Authority. Allocating medical SIFTR within Camberwell DHA. London: London Economics (for Camberwell Health Authority), 1991

5 Chartered Institute of Public Finance and Accountancy. Health database 1991. London: CIPFA, 1991.

(Accepted 27 March 1992) 